Polymer Journa1, Vol. 8, No. 5, pp 475-476 (1976)

SHORT COMMUNICATION

\title{
Effect of Polymer-Filler Interaction on Glass Transition Temperature
}

\author{
Jun'etsu SETo \\ SONY Corporation Research Center, 174 Fujitsuka-cho, \\ Hodogaya-ku, Yokohama 240, Japan. \\ (Received February 2, 1976)
}

KEY WORDS Glass Transition Temperature / Copolymer / $\alpha$-hema-
tite / Composite / Polymer-Filler Interaction /

The glass transition temperature $\left(T_{\mathrm{g}}\right)$ is one of the important parameters for the characterization of a polymer, and is affected by the addition of filler.

Many workers ${ }^{1-5}$ have suggested that $T_{\mathrm{g}}$ is affected by the polymer-filler interaction, i.e., the adsorption of polymer on the filler at the interface brings about a considerable decrease in the mobility or flexibility of the polymer chains. This decrease causes the shift of $T_{\mathrm{g}}$ towards a higher temperature.

However, Kumins, et al., ${ }^{6}$ reported the lowering of $T_{\mathrm{g}}$ for vinyl chloride-vinyl acetate copolymer containing the fine powder of rutile. They attributed their result to the breaking of interchain bonding caused by the adsorption of acetate groups on the filler; the breaking produced a more flexible back bone.

In this paper, the effect of the pretreatment of coating of a monomolecular layer of oleate onto the filler on the $T_{\mathrm{g}}$ of the same kind of polymer is described. No adsorption was observed and $T_{\mathrm{g}}$ was significantly raised for the treated filler, while some adsorption was observed and $T_{\mathrm{g}}$ decreased for the untreated filler, similar to the result reported by Kumins, et al. Our experimental results are discussed in terms of the polymer-filler interaction.

The polymer used was vinyl chloride-vinyl acetate copolymer with a composition of $87-\%$ vinyl chloride and 13-\% vinyl acetate. The number-average molecular weight was determined to be 24,400 by the osmotic pressure method.

The $\alpha$-hematite $\left(\mathrm{Fe}_{2} \mathrm{O}_{3}\right)$ powder which was used as the filler had a specific surface area of $14.1 \mathrm{~m}^{2} / \mathrm{g}$ and a particle size in the range of $0.05-0.5$ microns in diameter. The pretreatment of the filler, coating with oleate, was done using sodium oleate. ${ }^{8}$ The paints were made by mixing various amounts of the powder with a methyl ethyl ketone solution of the polymer on a ball mill; they were coated on glass plates and dried in vacuo for a week.

The loss modulus was measured at $110 \mathrm{~Hz}$ by a vibron direct reading viscoelastometer (Toyo Measuring Instrument Co., Tokyo, Japan). $T_{\mathrm{g}}$ was determined as the temperature of the maximum in the plots of the loss modulus as a function of temperature.

The maximum amount of polymer adsorption on the filler from methyl ethyl ketone solution was obtained by measuring the concentrations of the polymer before and after adsorption by means of the viscosity method.

Figure 1 shows typical plots of loss modulus $G^{\prime \prime} v s$. temperature for an unfilled polymer film and two kinds of filled films whose filler content is is $20.9 \mathrm{vol} \%$. $\quad T_{\mathrm{g}}$ and the adsorption of polymer for the various systems are listed in Table I. $T_{\mathrm{g}}$ of the film containing 20.9 vol $\%$ of the treated filler shifts to a significantly higher temperature as compared with that of the unfilled film. Adsorption was observed only in the untreated filler. The increase of $T_{\mathrm{g}}$ without adsorption of polymer is a remarkable point compared to the previous reports.

It is reported that in this copolymer the acetate groups bring about interchain bonding, and also play an important role in the process of the adsorption on the filler. ${ }^{7}$ The concentration 


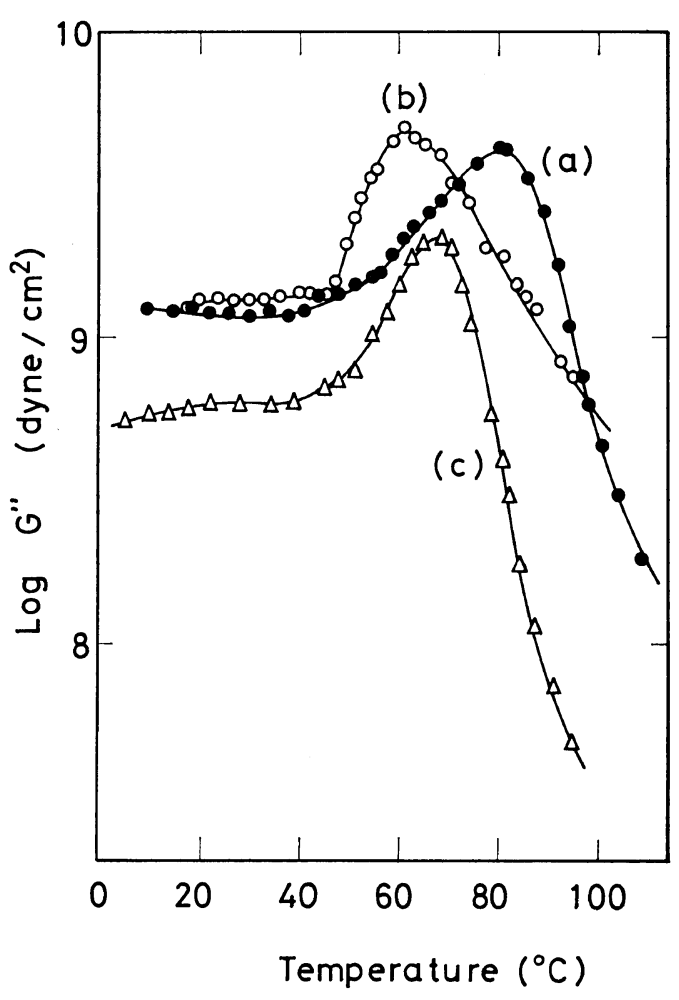

Figure 1. Temperature dependence of loss modulus $G^{\prime \prime}$ at $110 \mathrm{~Hz}$ for vinyl chloride-vinyl acetate copolymer films: (a) Filled with 20.9 vol\% of sodium oleate treated $\alpha$-hematite; (b) filled with the same amount of untreated $\alpha$-hematite; (c) unfilled.

of acetate groups would vary at the interface due to the changes of the surface properties of the filler. The configuration of polymer chains is then varied and the segments change to either a more flexible or an immobile state.

In the case of the treated filler, its surface acquires a hydrophobic property. The concentration of the acetate groups should decrease in the surface layer of filler and increase in the resultant polymer layer outside of the surface
Table I. Glass transition temperature $T_{\mathrm{g}}$ and adsorption for the filled polymers

\begin{tabular}{clcl}
\hline $\begin{array}{c}\mathrm{Fe}_{2} \mathrm{O}_{3} \\
\text { content, } \\
\text { vol\% } \%\end{array}$ & Pretreatment & $\begin{array}{c}T_{\mathrm{g}}, \\
{ }^{\circ} \mathrm{C}\end{array}$ & $\begin{array}{c}\text { Adsorption, } \\
\mathrm{g} / \mathrm{g} \mathrm{film}\end{array}$ \\
\hline 11.7 & Sodium oleate & 66 & None \\
20.9 & Sodium oleate & 80 & None \\
11.7 & Untreated & 58 & $0.67 \times 10^{-3}$ \\
20.9 & Untreated & 61 & $1.00 \times 10^{-3}$ \\
0 & & 67 & - \\
\hline
\end{tabular}

layer. Therefore, $T_{\mathrm{g}}$ should be shifted to a higher temperature, because the $T_{\mathrm{g}}$ of the filled film is determined by the $T_{\mathrm{g}}$ of the latter layer which occupies the larger volume fraction. It is not clear why the $T_{\mathrm{g}}$ of the film containing 11.7 vol\% of treated filler is $1^{\circ} \mathrm{C}$ lower than that of the unfilled film. In the case of the film with untreated filler, $T_{\mathrm{g}}$ should be shifted to lower temperature, because its surface is hydrophilic.

Acknowledgment. The Author wishes to thank Y. Makino for reading the manuscript.

\section{REFERENCES}

1. A. Yim and L. E. St. Pierre, Polym. Letters, 7, 237 (1963).

2. A. Yim, R. S. Chahal, and L. E. St. Pierre, J. Colloid and Interface Sci., 43, 583 (1973).

3. P. P. A. Smit, Rheol. Acta, 5, 277 (1966).

4. E. Price, D. M. French, A. S. Tompa, J. Appl. Polym. Sci., 16, 157 (1972).

5. J. Seto, Abstracts, 22nd Symposium on Rheology, Sendai, Japan, Oct. 2, 1974, p 27.

6. C. A. Kumins and Roteman, J. Polym. Sci., Part A, 1, 527 (1963).

7. C. A. Kumins and Roteman, idid, 55, 699 (1961).

8. T. Sato and J. Shimoiizaka, Funtai, Funmatsuyakin (J. Japan Soc. Powder and Powder Metallurgy), 12, 139 (1965). 